Bioscientia Medicina: Journal of Biomedicine \& Translational Research

Journal Homepage: www.bioscmed.com

\title{
Functional Outcome After Neglected Injury in Pediatric Softball Players Measured by Quickdash Score
}

\author{
Yoyos Dias Ismiarto1*, Sabdillah FT'1, Ramli F1, Kemas Abdul Mutholib Luthfi1
}

${ }^{1}$ Department of Orthopedics \& Traumatics, Faculty of Medicine, Universitas Padjajaran/RSUP Hasan Sadikin, Indonesia

\author{
Keywords: \\ Injury \\ Neglected \\ QuickDASH \\ Softball \\ Sport
}

A R T I C L E I N F O

\section{Corresponding author:}

E-mail-address: yoyosismiartounpad@gmail.com

(Yoyos Dias Ismiarto)

All authors have reviewed and approved the final version of the manuscript.

https://doi.org/10.32539/bsm.v4i4.171

\begin{abstract}
A B S T R A C T
Introduction. Pediatric softball players are prone to get injured as a result of high forces motions, with improper technique. Low communication and school-age often leads the injury became neglected. The aim of this study is to determine the incidence of Neglected injury in pediatric softball players in Bandung during a single season year of 2019. Methods. The study was conducted in softball clubs in Bandung. The inclusion is the softball players aged 18 years old or below, grouped into; (1) never injured, (2) neglected injury by non-professional/traditional massage, and (3) untreated neglected injury/rest only. The samples were evaluated with the Quick Disabilities of the Arm Shoulder and Hand outcome questionnaire (QuickDASH). Data was analyzed with Anova test. Results. Among the 50 players, aged from 12 to 18 years old, 36 players $(72 \%)$ were at group 1,8 players $(16 \%)$ were at group 2 and 6 players $(12 \%)$ were at group 3 . Most site of injuries for group 2 are at shoulder $(62,5 \%)$ and group 3 are at elbow $(66,6 \%)$. Significant differrences were identified between three groups with $\mathrm{p}=0.001$. The highest quickDASH score are in group $2(38,6)$, and the lowest are in group $1(0,0)$. Conclussion. All of the quickDASH Score in this group of age are categorized in mild difficulty. Those whom treated by non-professional has lower functional outcome compared to never injured and untreated injured players.
\end{abstract}

\section{Introduction}

Softball is one of popular sports for children in Indonesia. Although sports participation offers many benefits, this sports also pose a risk for injury. Pediatric softball players are prone to get injured as a result of high forces motions ${ }^{1}$, with improper technique. Low communication and school-age often leads the injury became neglected. The aim of this study is to determine the incidence of Neglected injury in pediatric softball players in Bandung during a single season year of 2019.

With an estimated 4.8 million children 5 to
14 years of age participating annually in organized and recreational baseball and softball. Highly publicized catastrophic impact injuries from contact with a ball or a bat frequently raise safety concerns. ${ }^{2}$ These injuries, as well as ongoing concerns about shoulder and elbow injuries, provide the impetus for this review of the safety of baseball for 5- to 14-year-old participants. The discussion focuses principally on baseball, but softball is considered in accord with the availability of relevant literature. This statement mainly concerns injuries during practices and games in organized settings. 
Players and bystanders also can be injured in casual play.

There are 7.4 million student athletes in the United States.. A recent study found that boys' baseball and girls' softball players sustained 1 injury per 1000 practices or competitions. ${ }^{2}$ In addition, the number of high school pitchers who require surgery for pitching-related injuries has increased. ${ }^{3}$ The number of softball athletes has doubled in the past 2 decades.4 The Amateur Softball Association of America annually registers more than 83000 youth girls' fastpitch softball teams comprising more than 1.2 million girls. Arm overuse injuries are common in baseball and softball, especially among pitchers. Approximately one fourth of high school baseball players pitch. The repetitive, unnatural form of baseball pitching results in a high risk for overuse injuries.5,6 It is thought that the underhand, windmill delivery used in fastpitch softball creates less arm stress compared with the overhand delivery in baseball. In addition, the distance between the pitching mound and the home plate is shorter in softball (40.0 ft) compared with baseball (60.5 ft); however, studies have found that the stress placed on the shoulders of softball pitchers is similar to that placed on baseball pitchers. ${ }^{2}$ Risk factors for shoulder injuries in adolescent baseball pitchers include pitching more games, months, and pitches per year; more innings and pitches per game; and more warm-up pitches before games than their noninjured counterparts. Injured pitchers were also more frequently started as pitchers, pitched with higher velocity, and pitched more often with arm fatigue and pain. ${ }^{3,7}$ Our objective was to describe and compare high school baseball and softball shoulder injury rates and patterns. As the number of high school athletes grows, the incidence of these injuries is also likely to increase. Improving our knowledge of common injuries and possible means for prevention is crucial for players and coaches to maintain healthy high school athletes.

The overall incidence of injury in baseball ranges between $2 \%$ and $8 \%$ of participants per year. Among children 5 to 14 years of age, an estimated 162000 baseball, softball, and tee-ball injuries were treated in emergency departments in 1995.8 The number of injuries generally increased with age, with a peak incidence at 12 years. Of the injuries, $26 \%$ were fractures, and $37 \%$ were contusions and abrasions. The remainder were strains, sprains, concussions, internal injuries, and dental injuries.1 The potential for catastrophic injury resulting from direct contact with a bat, baseball, or softball exists. Deaths have occurred from impact to the head resulting in intracranial bleeding and from blunt chest impact, probably causing ventricular fibrillation or asystole (commotio cordis). ${ }^{9} 1$ Children 5 to 15 years of age seem to be uniquely vulnerable to blunt chest impact because their thoraces may be more elastic and more easily compressed.2 Statistics compiled by the US Consumer Product Safety Commission 1 indicate that there were 88 baseball-related deaths to children in this age group between 1973 and 1995, an average of about 4 per year. This average has not changed since 1973. Of these, 43\% were from direct-ball impact with the chest (commotio cordis); 24\% were from directball contact with the head; $15 \%$ were from impacts from bats; $10 \%$ were from direct contact with a ball impacting the neck, ears, or throat; and in $8 \%$, the mechanism of 
injury was unknown. ${ }^{10}$ Direct contact by the ball is the most frequent cause of death and serious injury in baseball. Preventive measures to protect young players from direct ball contact include the use of batting helmets and face protectors while at bat and on base, the use of special equipment for the catcher (helmet, mask, chest, and neck protectors), the elimination of the on-deck circle, and protective screening of dugouts and benches. ${ }^{3,5}$

The term "Little League elbow" refers to medial elbow pain attributable to throwing by skeletally immature athletes. Pitchers are most likely to be affected by this condition, but it can occur in other positions associated with frequent and forceful throwing. The throwing motion creates traction forces on the medial portion of the elbow and compression forces on the lateral portion of the elbow.5,8 The medial traction forces can cause separation or avulsion of the apophysis from the medial epicondyle of the humerus and overuse injury to the common flexor tendon. The compression forces laterally can cause collapse and deformity of the distal humerus, also known as osteochondritis dissecans of the capitulum of the humerus. 6 Early recognition of the symptoms is important to avoid chronic elbow pain, instability, and arthritis. In response to concerns about Little League elbow and shoulder, many youth leagues have attempted to limit the stress placed on the pitching arms of youth. For example, Little League Baseball Incorporated limits pitchers to a maximum of 6 innings per week and requires mandatory rest periods between pitching appearances. ${ }^{3}$ The number of pitches thrown per outing should be recorded for all young pitchers. Recommendations include limiting the number of pitches to 200 per week, or 90 pitches per outing. ${ }^{4}$ A preseason conditioning program that includes strengthening the rotator cuff and the shoulder-stabilizing muscles also may help reduce throwing injuries. Instruction on proper pitching mechanics is another way to prevent serious overuse throwing injuries. 5 Finally, allowing time during the early part of the season to gradually increase the amount and intensity of throwing may allow young arms a better opportunity to adapt to the stresses of throwing. ${ }^{6}$

\section{Methods}

The study was conducted in softball clubs in Bandung. The inclusion is the softball players aged 18 years old or below, grouped into; (1) never injured, (2) neglected injury by nonprofessional/traditional massage, and (3) untreated neglected injury/rest only. The samples were evaluated with the Quick Disabilities of the Arm Shoulder and Hand outcome questionnaire (QuickDASH). Data was analyzed with Anova test.

\section{Results}

Among the 50 players, aged from 12 to 18 years old, 36 players (72\%) were at group 1,8 players $(16 \%)$ were at group 2 and 6 players $(12 \%)$ were at group 3. Most site of injuries for group 2 are at shoulder $(62,5 \%)$ and group 3 are at elbow $(66,6 \%)$. Significant differrences were identified between three groups with $\mathrm{p}=0.001$. The highest quickDASH score are in group 2 $(38,6)$, and the lowest are in group $1(0,0)$. 


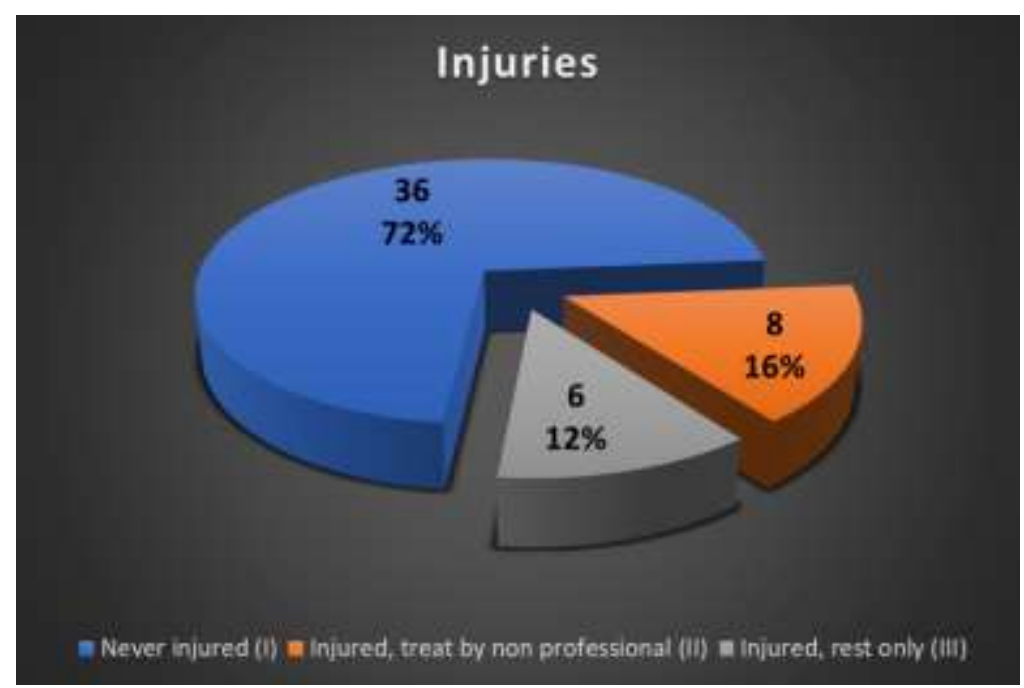

Figure 1. Group of Sample

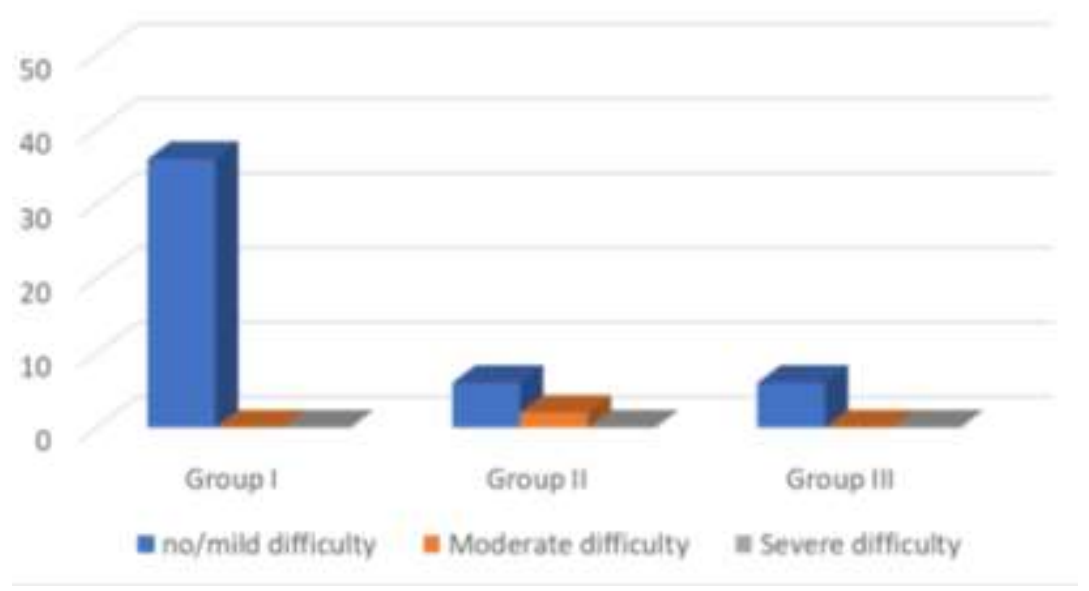

Figure 2. QuickDASH Score

\section{Discussions}

The aim of this study was to evaluate the differences in QuickDASH scores between groups of children who had never had an upper limb injury, had an injury and were treated by non-professional personnel and had neglected or untreated injuries. The results of this study indicate that the highest QuickDASH scores were found in the first group who had no injury. An interesting result is shown in the scores between the second and third groups, where the group that received treatment from nonprofessional personnel had a higher rate of disability than those with neglected or untreated injuries.

Several studies have reported that the treatment of injuries performed by non-professional personnel such as chiropractors or masseuses has a worse complication rate and outcome compared to treatment performed by medical professionals.11,12 Actions such as manipulation and excessive splinting often lead to infection and malfunctioning of an extremity. ${ }^{11}$

In pediatric patients with LLS, conservative management can still provide good results to prevent recurrent pain. Conservative treatment for LLS includes resting or stopping throwing activities for at least 3 months. ${ }^{13}$ However, a study by Harada et al. Confirms that conservative management with rest less than 2 months has shown a fairly high pain recurrence rate. outcome assessment that can be measured using the quick DASH score. 
Orthopedic injury of the upper limb is a fairly common injury in the pediatric population. With the high incidence of upper limb injury in children, an accurate assessment is needed to determine the impact on the child's functional status as well as his overall health. 15

\section{Conclusion}

All of the quickDASH Score in this group of age are categorized in mild difficulty. Those whom treated by non-professional has lower functional outcome compared to never injured and untreated injured players.

\section{References}

1. McLean, S. D.. 2005. Congenital Anomalies. Dalam MacDonald, Mhairi G., M. M. K. Seshia, M. D. Mullett (Eds.). Avery's Neonatology, ed. 6. Lippincott Williams \& Wilkins

2. Liu, L., S. Oza, D. Hogan, J. Perin, I. Rudan, J. E. Lawn, et al. 2015. Global, regional, and national causes of child mortality in 2000-2013, with projections to inform post-2015 priorities: an updated systematic analysis. Lancet, 2015; 385: 430-40

3. WHO. 2013. Indonesia: Neonatal and Child Health Profile.

4. WHO. 2015. Congenital anomalies: Fact Sheet

5. Yuncie, S. M., S. M. Sarumpaet, Jemadi. 2013. Karakteristik Ibu Yang Melahirkan Bayi Dengan Kelainan Kongenital Di Rsud Dr. Pirngadi Medan Tahun 2007-2011. FKM USU

6. WHO. 2013. Prevention and Control of Birth Defects in South-East Asia Region: Strategic Framework (2013-2017)

7. Fung, A., C. Manlhiot, S. Naik, H. Rosenberg, J. Smythe, J. Lougheed, et al. 2013. Impact of Prenatal Risk Factors on Congenital Heart Disease in the Current Era. J Am Heart Assoc. 2013; 2: e000064
8. Figueiredo, J. C., S. Ly, K. S. Magee, U. Ihenacho, J. W. Baurley, P. A. Sanchez-Lara, et al. 2015. Parental Risk Factors for Oral Clefts among Central Africans, Southeast Asians, and Central Americans. Birth Defects Research 2015; 103: 863-79.

9. Ucar, M. G., T. T. Ilhan, A. Gul, Z. S. Sert, C. Celik. 2015. Cleft lip and cleft palate: a disease with multiple risk factors in a pregnant woman. Int J Reprod Contracept Obstet Gynecol. 2015 Dec; 4(6): 2044-46

10. Kumar, P. Dysmorphology. Dalam Kumar, P., B. K. Burton (Eds.). 2008. Congenital Malformations: Evidence-Based Evaluation and Management. McGraw-Hill

11. Hacksaw, A., C. Rodeck, S. Boniface. 2011. Maternal smoking in pregnancy and congenital disabilities: a systematic review based on 173 687 malformed cases and 11.7 million controls. Human Reproduction Update, Vol.0, No.0 pp. 116,2010

12. Sabbagh, H. J., M. H. A. Hassan, N. P. T. Innes, H. M. Elkodary, J. Little, P. A. Mossey. 2015. Passive Smoking in the Etiology of Non-Syndromic Orofacial Clefts: A Systematic Review and MetaAnalysis. PLoS ONE 10(3): e0116963

13. Zwink, N., E. Jenetzky, H. Brenner. 2011. Parental risk factors and anorectal malformations: systematic review and metaanalysis. Orphanet Journal of Rare Diseases 2011; 6: 25

14. Stoll, C., Y. Alembik, M. P. Roth, B. Dott. Risk factors in congenital anal atresias. Annales de Genetique 1997; 40(4): 197-204

15. van Rooij, I. A. L. M., C. H. W. Wijers, P. N. M. A. Rieu, H. S. Hendriks, M. M. Brouwers, N. V. Knoers, et al. 2010. Maternal and paternal risk factors for anorectal malformations: A Dutch casecontrol study. Birth Defects Res A Clin Mol Teratol 2010; 88(3): 152-8 